\title{
COVID-19 screening before gastrointestinal procedures
}

\author{
Ahmed Eliwa ${ }^{1 *} \mathbb{D}$, Osman Mohamed Osman ${ }^{1}$, Ahmed Helal ${ }^{1}$, Abdelgawad Saied Mohamed ${ }^{1}$, \\ Mohammed ElFayoumie', Ramadan Eldamarawy', Sadek Mostafa', Ashraf Elsharkawy ', Khaled S. Makboul', \\ Salwa I. Elshennawy ${ }^{2}$, Mahmoud Abdelhady ${ }^{3}$ and Ashraf Elbahrawy ${ }^{1}$
}

\begin{abstract}
Background: In March 2020, the World Health Organization declared coronavirus 2019 (COVID-19) a global pandemic. We aimed to assess the ability of COVID-19 screening to detect preprocedural infection at the gastrointestinal units. One hundred and three patients indicated for gastrointestinal tract interventional procedures were included. All patients surveyed for COVID-19-related symptoms and COVID-19 rapid IgM/lgG antibodies. Symptomatic and COVID19 antibody-positive patients further tested for COVID-19 reverse transcriptase by polymerase chain reaction (RT-PCR). All patients contacted, 14 days after the procedure and asked about the possible development of COVID-19. All health care workers (HCWs) $(n=18)$ were screened weekly for COVID-19-related symptoms.
\end{abstract}

Results: The mean age was $46.11 \pm 17.16$ years of them $58.25 \%$ were males. $2.9 \%$ patients had COVID-19-related symptoms and $97.1 \%$ were asymptomatic. All symptomatic patients tested positive for COVID-19 IgM antibody and RT-PCR. Among asymptomatic patients 23\% had positive COVID-19 antibodies, of them 56.5\%patients had positive RT-PCR. One HCW developed COVID-19 during the study. None of the included patients developed new onset of COVID-19 infection, two weeks after the procedure.

Conclusion: COVID-19 antibody test may be a reasonable preprocedural screening method for low-income countries and COVID-19 RT-PCR screening for symptomatic patients and those with positive COVID-19 antibody test.

Keywords: COVID-19, Endoscopy, GIT, COVID-19 antibody, RT-PCR, Pandemic

\section{Background}

In 2019, a new coronavirus, SARS-CoV-2 leading to coronavirus disease 2019 (COVID-19), has rapidly disseminated around the world [1]. The World Health Organization (WHO) declared COVID-19 a pandemic on March 11, 2020 [2]. On February 14, 2020, Egypt announced the first diagnosed case of COVID-19. After that, the number of daily reported cases continued to rise [3].

Worldwide, this pandemic has had a significant impact on gastrointestinal practices, with an approximately $83 \%$

\footnotetext{
*Correspondence: Ahmedmaher.206@azhar.edu.eg

${ }^{1}$ Department of Internal Medicine, Al-Azhar University, Nasr City, Cairo

11884, Egypt

Full list of author information is available at the end of the article
}

reduction in endoscopic procedures [4]. Similar overall reductions in endoscopic procedures have been seen in Italy in nationwide multicentric studies as well as in Pakistan $[5,6]$. Gastroenterology staff may be at an increased risk for acquiring COVID-19 because the virus is detectable in the GIT [7], and endoscopy is an aerosol-generating procedur e[8].. Recommendations have been issued to guide personal protective equipment (PPE) use [9] and the triage of procedural urgency [10]. There are many positive impacts of preprocedure testing for COVID-19, such as categorization of patient risk, the use of appropriate PPE, and decreasing the spread of the virus to patients and HCWs.

Ideally, all patients having gastrointestinal procedures would be required to undergo testing to confirm or 
exclude active viral infection by reverse transcriptase polymerase chain reaction (RT-PCR). There is currently no national policy for preprocedural screening of patients during the COVID-19 pandemic in Egypt. Due to the current limited supply of available testing kits along with the cost involved, we used a combination of COVID-19 symptoms and COVID-19 rapid IgM/IgG antibody levels for prescreening of patients who had indications for gastrointestinal procedures.

\section{Methods}

We aimed to assess the ability of COVID-19 screening tools using patients' symptoms and preprocedure COVID-19 antibody test to detect preprocedural infection and to prevent nosocomial COVID-19 at gastroenterology units.

This prospective cross-sectional study was conducted at Al Hussein University Hospital, Cairo, Egypt, between April 1 and August 1, 2020. The study was approved by the ethical committee of Faculty of Medicine, Al-Azhar University, Cairo, Egypt (Med._147Med.Research. COVID-19 Screening Before Gastrointestinal Procedures. 00000175). Informed consent was obtained from all individual participants included in the study. Among 144 patients who underwent gastrointestinal procedures, 41 patients were not tested for COVID-19 antibodies and excluded from the study. Finally, 103 patients surveyed for COVID-19 symptoms and COVID-19 rapid IgM/IgG antibodies were included.

All patients who had indications for diagnostic and/ or therapeutic gastrointestinal procedures $(n=103)$ underwent prescreening for COVID-19 symptoms. In addition, the occurrence of postprocedure COVID-19 infection was assessed among the included patients and medical staff members working in the gastrointestinal unit $(n=18)$ to assess the efficiency of the proposed prescreening method. Patients who were not tested for COVID-19 antibodies were excluded.

\section{Prescreening for COVID-19}

Prescreening included a clinical survey for COVID19-related symptoms and COVID-19 rapid IgM/IgG antibody testing ( $n=103$ patients). COVID-19-related symptoms included fever $\geq 38^{\circ} \mathrm{C}$, cough, dyspnea, sore throat, anosmia, loss of taste, diarrhea, fatigue, myalgia, history of recent travel, and history of contact with COVID-19-infected patients within 2 weeks before the procedure [10]. Also, complete blood count looking for lymphopenia (below $1.0 \times 10^{9} / \mathrm{L}$ ), C-reactive protein (CRP) (positive more than $6 \mathrm{mg} / \mathrm{L}$ ), and CT chest were done for all patients before procedures. Patients with COVID-19-related symptoms and/or positive COVID-19 antibodies were further tested with RT-PCR to confirm COVID-19.

\section{Postprocedure screening for COVID-19}

All patients were contacted (by phone) 14 days after the procedure and asked about the possible development of COVID-19 symptoms [11, 12]. The postprocedural diagnosis of COVID-19 infection was based on a new onset of fever $\geq 38^{\circ} \mathrm{C}$ and two or more new symptoms: cough, sore throat, dyspnea, anosmia, loss of taste, and diarrhea [13]. Patients with suspected symptoms of COVID-19 were referred to COVID-19 treatment centers.

All HCWs $(n=18)$ were screened weekly for COVID19-related symptoms. In the setting of a highly suspected COVID-19 [13], the clinical diagnosis was further confirmed by COVID-19 rapid IgM/IgG antibodies and the COVID-19 RT-PCR. Infected HCWs discharged from duty and referred for treatment.

\section{COVID-19 detection by rapid IgM/lgG}

SARS-CoV-2 antibodies were detected by a COVID$19 \mathrm{IgM} / \mathrm{IgG}$ antibody rapid diagnostic test (SGTi-flex COVID-19 IgM/IgG, Sugentech, South Korea). It is a qualitative immunoassay for the rapid detection of both anti-SARS-CoV-2-IgM and anti-SARS-CoV-2-IgG in the venous blood or plasma with a sensitivity of $92.43 \%$ and a specificity of $99.15 \%$, as reported by the manufacturer. The results were analyzed visually after $15-20 \mathrm{~min}$.

\section{COVID-19 detection by RT-PCR}

Nasopharyngeal swabs were collected for COVID-19 RT-PCR testing as described previously [14]. Briefly, probes were annealed to three target sequences specific to COVID-19: ORF1ab, nucleocapsid (N), and spike (S) primers/probes for bacteriophage MS2. Two of the three genes and the MS2 (positive control) had to be positive for a diagnosis of COVID-19.

\section{Categorization of procedure urgency}

All procedures were categorized as urgent $(8-24 \mathrm{~h})$, semiurgent ( $24 \mathrm{~h}-7$ weeks), and elective ( $\geq 8$ weeks) based on the following indications.

Indications of urgent (8-24 h) endoscopic procedures included upper GIT bleeding, food bolus impaction, lower GIT bleeding (hemodynamically unstable), acute intestinal obstruction, cholangitis with sepsis/septic shock, and biliary leakage. Urgent percutaneous transhepatic drainage (PTD) was indicated in cholangitis with sepsis/septic shock and biliary leakage.

Semiurgent ( $24 \mathrm{~h}$ to 7 weeks) endoscopic procedures were indicated in the following situations: gastric cancer diagnosis, acute-onset dysphagia, lower GIT bleeding (hemodynamically stable), partial intestinal 
obstruction, new-onset bloody diarrhea with negative cultures, inflammatory bowel disease flare, choledocholithiasis with/without cholangitis, biliary pancreatitis with/without cholangitis, concerns for pancreatic cancer or cholangiocarcinoma, and small-bowel bleeding. Semiurgent indications for radiofrequency ablation (RFA) and transarterial chemoembolization (TACE) included active hepatocellular carcinoma (HCC). Semiurgent liver biopsy was performed for patients with ongoing hepatitis and for those with potentially malignant liver lesions. Semiurgent pigtail insertion and PTD were indicated in patients with active hydatid cysts, choledocholithiasis with or without cholangitis, and biliary pancreatitis with or without cholangitis.

Elective ( $\geq 8$ weeks) endoscopic procedures were performed for the following indications: ampullary adenoma, isolated weight loss, heartburn, dyspepsia/ noncardiac chest pain, established dysphagia, Barrett's esophagus, esophageal varices evaluation or follow-up banding, iron-deficiency anemia, percutaneous endoscopic gastrostomy (PEG) tube placement, chronic diarrhea, colorectal cancer screening, ulcerative colitis with dysplasia, biliary stent replacement, concerns for submucosal mass, double duct sign without a discrete mass, concerns for neuroendocrine tumor, pancreatic cyst evaluation, and small-bowel tumor. Elective pigtail insertion was performed in patients with symptomatic simple liver cysts.

\section{Precautions to prevent infection during gastrointestinal procedures}

Based on the COVID-19 RT-PCR results of the included patients, HCWs likely followed the recommended precautions to protect against infection. If patients were negative on COVID-19 RT-PCR, HCWs wore a hair net, surgical mask, face shield, single-use gown, and single pair of gloves. If patients were positive on COVID-19 RT-PCR, the HCWs wore a hair net, N-95 or FFP, 2/3 surgical mask, face shield and goggles, full-sleeve gown, a double layer of gloves, and shoe covers. All rooms were non-negative-pressure and were disinfected at the end of each procedure. All patients wore surgical masks (except during procedures).

\section{Statistical analysis}

Data were analyzed using the statistical package for social sciences, version 20.0 (SPSS Inc., Chicago, Illinois, USA). Quantitative data are expressed as the mean \pm standard deviation (SD). Qualitative data are expressed as frequencies and percentages.

\section{Results}

Among 144 patients who underwent gastrointestinal procedures, 41 patients were not tested for COVID19 antibodies and excluded from the study. Finally, 103 patients surveyed for COVID-19 symptoms and COVID-19 rapid IgM/IgG antibodies were included. The mean age of the included patients was $46.11 \pm$ 17.16 years, and there were $60(58.25 \%)$ males and $43(42.75 \%)$ females (Table 1). Among 103 patients, COVID-19 antibodies were detected in 26 patients (25.3\%), of whom 16 (61.5\%) tested positive by RT-PCR.

A total of 103 gastrointestinal procedures were performed. These included EGD $(n=44)$, colonoscopies $(n=25)$, ERCP $(n=12)$, EUS $(n=7)$, PEG $(n=1)$, DBE $(n=1)$, liver biopsies $(n=2)$, pigtails $(n=3)$, PTD $(n=2)$, RFA $(n=3)$, and TACE $(n=3)$.

\section{Procedure urgency}

Twenty-four (23.3\%), 28 (27.2\%), and 51 (49.5\%) patients underwent urgent, semiurgent, and elective procedures, respectively (Table 1 ).

\section{Symptomatic patients}

Three patients had COVID-19-related symptoms prior to the gastrointestinal procedure. These symptoms included fever $\geq 38^{\circ} \mathrm{C}(n=1)$, fever $\geq 38^{\circ} \mathrm{C}$ and dyspnea $(n=1)$, and fever $\geq 38^{\circ} \mathrm{C}$ and diarrhea $(n=1)$. All symptomatic patients tested positive for COVID-19 IgM and RT-PCR. COVID-19 IgG was omitted as they are symptomatic.

\section{Asymptomatic patients}

Among 100 asymptomatic patients, 23 had COVID19-positive serology. Of them, 4, 8, and 11 were positive for IgM only, IgG only, and both IgM and IgG, respectively.

The frequency of diabetes mellitus and elevated CRP levels were significantly higher among asymptomatic patients who were positive for COVID-19 antibodies $(P$ $<0.05$ ) (Table 2).

Among 23 asymptomatic patients positive with COVID-19 rapid IgM/IgG antibodies, 13 patients (56.5\%) had COVID-19, as detected by RT-PCR. The detection of COVID-19 on RT-PCR was significantly related with older age, gender, and the presence of COVID-19 IgM antibodies $(P<0.05)$ (Table 3$)$. The frequency of IgM and the simultaneous presence of IgM and IgG among RT-PCR-positive patients were 15.4\% $(n=2)$ and $84.6 \%(n=11)$, respectively (Table 3$)$

\section{Postprocedure COVID-19-infected patients}

None of the preprocedural COVID-19 antibody negative patients $(n=77)$ developed new onset of 
Table 1 Characteristics of included patients

\begin{tabular}{|c|c|}
\hline $\begin{array}{l}\text { Age } \\
\text { Mean } \pm \text { SD (range) }\end{array}$ & $46.11 \pm 17.16(15-80)$ \\
\hline \multicolumn{2}{|l|}{ Gender } \\
\hline Males & $60(58.25 \%)$ \\
\hline Females & $43(41.75 \%)$ \\
\hline \multicolumn{2}{|l|}{ Performed procedure } \\
\hline Esophago-gastro duodenoscopy (OGD) & $44(42.7 \%)$ \\
\hline Percutaneous endoscopic gastrostomy (PEG) tube insertion & $1(0.97 \%)$ \\
\hline Colonoscopy & $25(24.27 \%)$ \\
\hline Enteroscopy & $1(0.97 \%)$ \\
\hline Endoscopic retrograde cholangiopancreatography (ERCP) & $12(11.65 \%)$ \\
\hline Endoscopic ultrasound (EUS) & $7(6.8 \%)$ \\
\hline Pigtail & $3(2.9 \%)$ \\
\hline Percutaneous transhepatic drainage (PTD) & $2(1.94 \%)$ \\
\hline Liver biopsy & $2(1.94 \%)$ \\
\hline Radiofrequency ablation (RFA) & $3(2.9 \%)$ \\
\hline Trans-arterial chemoembolization (TACE) & $3(2.9 \%)$ \\
\hline \multicolumn{2}{|l|}{ Procedure emergency } \\
\hline Urgent & $24(23.3 \%)$ \\
\hline Semi-urgent & $28(27.2 \%)$ \\
\hline Elective & $51(49.5 \%)$ \\
\hline COVID-19-related symptomatic & $3(2.9 \%)$ \\
\hline Fever $\geq 38^{\circ} \mathrm{C}$ only & $1(0.97 \%)$ \\
\hline Fever $\geq 38^{\circ} \mathrm{C}$ with dyspnea & $1(0.97 \%)$ \\
\hline Fever $\geq 38^{\circ} \mathrm{C}$ with diarrhea & $1(0.97 \%)$ \\
\hline \multicolumn{2}{|l|}{ Associated comorbidity } \\
\hline Diabetes mellitus & $13(12.6 \%)$ \\
\hline Hypertension & $8(7.76 \%)$ \\
\hline \multicolumn{2}{|l|}{ History of contact with COVID-19 patients } \\
\hline Yes & $0(0 \%)$ \\
\hline No & $103(100 \%)$ \\
\hline \multicolumn{2}{|l|}{ Laboratory tests } \\
\hline Lymphopenia & $16(11.1 \%)$ \\
\hline Elevated CRP & $25(24.3 \%)$ \\
\hline \multicolumn{2}{|l|}{ Chest CT findings of COVID-19 pneumonia } \\
\hline Yes & $2(1.9 \%)$ \\
\hline No & $101(98.1 \%)$ \\
\hline \multicolumn{2}{|l|}{ COVID-19 antibody } \\
\hline IgM-positive & $7(6.8 \%)$ \\
\hline IgG-positive & $8(7.8 \%)$ \\
\hline IgM and IgG-positive & $11(10.7 \%)$ \\
\hline IgM and IgG-negative & $77(74.7 \%)$ \\
\hline \multicolumn{2}{|l|}{ COVID-19 PCR $(n=26)$} \\
\hline Positive & $16(61.5 \%)$ \\
\hline Negative & $10(38.5 \%)$ \\
\hline \multicolumn{2}{|l|}{ COVID-19 infection after the procedures based on symptoms } \\
\hline Yes & $0(0 \%)$ \\
\hline No & $103(100 \%)$ \\
\hline
\end{tabular}


Table 2 Characteristics of asymptomatic patients $(n=100)$ positive for COVID-19 rapid lgM/lgG antibodies

\begin{tabular}{|c|c|c|c|c|c|c|c|}
\hline \multirow{2}{*}{ Age } & \multirow[b]{2}{*}{ Mean } & \multicolumn{2}{|c|}{$\begin{array}{l}\text { Asymptomatic COVID-19 Ab } \\
\text { negative } \\
(n=77)\end{array}$} & \multicolumn{2}{|c|}{$\begin{array}{l}\text { Asymptomatic COVID-19 Ab } \\
\text { positive } \\
(n=23)\end{array}$} & \multirow{3}{*}{$\begin{array}{l}\text { Test } \\
T=0.67\end{array}$} & \multirow{3}{*}{$\frac{p \text { value }}{}$} \\
\hline & & 45.4 & & 48.2 & & & \\
\hline & $\pm \mathrm{SD}$ & 17.02 & & 17.6 & & & \\
\hline \multirow[t]{2}{*}{ Sex } & Male & 49 & $63.6 \%$ & 10 & $43.5 \%$ & $x^{2}=2.9$ & 0.085 \\
\hline & Female & 28 & $36.4 \%$ & 13 & $56.5 \%$ & & \\
\hline \multirow[t]{3}{*}{ Procedure urgency } & Urgent & 19 & $24.7 \%$ & 4 & $17.4 \%$ & $x^{2}=0.64$ & 0.725 \\
\hline & Semi-urgent & 19 & $24.7 \%$ & 7 & $30.4 \%$ & & \\
\hline & Elective & 39 & $50.6 \%$ & 12 & $52.2 \%$ & & \\
\hline \multirow[t]{2}{*}{$\mathrm{DM}$} & No & 70 & $90.9 \%$ & 17 & $73.9 \%$ & $X^{2}=4.5$ & 0.033 \\
\hline & Yes & 7 & $9.1 \%$ & 6 & $26.1 \%$ & & \\
\hline \multirow[t]{2}{*}{ HTN } & No & 70 & $90.9 \%$ & 22 & $95.7 \%$ & $x^{2}=0.54$ & 0.462 \\
\hline & Yes & 7 & $9.1 \%$ & 1 & $4.3 \%$ & & \\
\hline \multirow[t]{2}{*}{ Lymphopenia } & No & 73 & $94.8 \%$ & 19 & $82.6 \%$ & $X^{2}=3.57$ & 0.059 \\
\hline & Yes & 4 & $5.2 \%$ & 4 & $17.4 \%$ & & \\
\hline \multirow[t]{2}{*}{ CRP } & Positive & 54 & $70.1 \%$ & 23 & $100 \%$ & $X^{2}=8.9$ & 0.003 \\
\hline & Negative & 23 & $29.9 \%$ & 0 & $0 \%$ & & \\
\hline \multirow[t]{2}{*}{ COVID-19 RT-PCR } & Negative & --- & --- & 10 & $43.5 \%$ & ------ & ----- \\
\hline & Positive & --- & --- & 13 & $56.5 \%$ & & \\
\hline
\end{tabular}

Table 3 Characteristic of asymptomatic $(n=13)$ patients positive for COVID-19 RT-PCR compared to asymptomatic $(n=10)$ patients negative for COVID-19 RT-PCR

\begin{tabular}{|c|c|c|c|c|c|c|c|}
\hline & & $\begin{array}{l}\text { Asym } \\
\text { PCR-p }\end{array}$ & $\begin{array}{l}\text { COVID-19 } \\
n=13)\end{array}$ & $\begin{array}{l}\text { Asyn } \\
\text { PCR }\end{array}$ & $\begin{array}{l}\text { ic COVID-19 } \\
(n=10)\end{array}$ & Test & $p$ value \\
\hline Age & Mean & 55.07 & & 39.2 & & $T=2.35$ & 0.028 \\
\hline & $\pm \mathrm{SD}$ & 15.5 & & 16.7 & & & \\
\hline Sex & Male & 8 & $61.5 \%$ & 2 & $20 \%$ & $x^{2}=3.9$ & 0.046 \\
\hline & Female & 5 & $38.5 \%$ & 8 & $80 \%$ & & \\
\hline Procedure & Urgent & 3 & $23.1 \%$ & 1 & $10 \%$ & $X^{2}=2.26$ & 0.322 \\
\hline & Semi-urgent & 5 & $38.5 \%$ & 2 & $20 \%$ & & \\
\hline & Elective & 5 & $38.5 \%$ & 7 & $70 \%$ & & \\
\hline DM & No & 9 & $69.2 \%$ & 8 & $80 \%$ & $x^{2}=0.34$ & 0.560 \\
\hline & Yes & 4 & $30.8 \%$ & 2 & $20 \%$ & & \\
\hline HTN & No & 13 & $100 \%$ & 9 & $90 \%$ & $x^{2}=1.35$ & 0.244 \\
\hline & Yes & 0 & $0 \%$ & 1 & $10 \%$ & & \\
\hline Lymphopenia & No & 11 & $84.6 \%$ & 8 & $80 \%$ & $x^{2}=0.084$ & 0.772 \\
\hline & Yes & 2 & $15.4 \%$ & 2 & $20 \%$ & & \\
\hline CRP & Negative & 13 & $100 \%$ & 10 & $100 \%$ & ----- & ----- \\
\hline & Positive & 0 & $0 \%$ & 0 & $0 \%$ & & \\
\hline COVID-19 IgM only & Negative & 11 & $84.6 \%$ & 8 & $80 \%$ & $X^{2}=0.83$ & 0.772 \\
\hline & Positive & 2 & $15.4 \%$ & 2 & $20 \%$ & & \\
\hline COVID-19 IgM and lgG & Negative & 2 & $15.4 \%$ & 10 & $100 \%$ & $X^{2}=16.2$ & $<0.001$ \\
\hline & Positive & 11 & $84.6 \%$ & 0 & $0 \%$ & & \\
\hline COVID-19 lgG only & Negative & 13 & $100 \%$ & 2 & $20 \%$ & $X^{2}=15.9$ & $<0.001$ \\
\hline & Positive & 0 & $0 \%$ & 8 & $80 \%$ & & \\
\hline
\end{tabular}


COVID-19-related symptoms 14 days after the procedures.

\section{Postprocedure COVID-19-infected HCW}

Among the $18 \mathrm{HCWs}$ included, the mean age was 38.3 \pm 8.7 years (range $25-54$ years). Of these HCWs, 10 (55.5\%) were males and 8 (44.4\%) were females. There were $10(55.5 \%)$ physicians, 7 (39\%) nurses, and 1 (5.5\%) cleaning worker. Of the HCWs, one (5.5\%) developed fever $\geq 38^{\circ} \mathrm{C}$, diarrhea, and sore throat and tested positive for COVID-19 IgG, IgM, and RT-PCR. Another $\mathrm{HCW}$ had lost taste and smell senses but tested negative for COVID-19 rapid IgM/IgG and RT-PCR. The outcome of the one COVID-19-infected HCW $(n=1)$ was a complete cure with no complications. However, this HCW stopped work duties for one month (Table 4).

Table 4 Demographic, clinical characteristics, and outcome of health care workers $(n=18)$

\begin{tabular}{ll}
\hline Age (years) & \\
Mean \pm SD (range) & $38.3 \pm 8.7(25-54)$ \\
Sex; $n$ (\%) & $10(55.6 \%)$ \\
Male & $8(44.4 \%)$ \\
Female & \\
Included health care workers; $n$ (\%) & $10(55.6 \%)$ \\
Physician & $7(38.9 \%)$ \\
Nurse & $1(5.5 \%)$ \\
Cleaning worker & \\
HCW working days during the pandemic $n(\%)$ & $9(50 \%)$ \\
$\leq 2$ days & $3(16.7 \%)$ \\
3-4 days & $6(33.3 \%)$ \\
$>4$ days & \\
HCWs with COVID-19 symptoms, $n(\%)$ & $1(5.5 \%)$ \\
Fever, diarrhea, and sore throat & $1(5.5 \%)$ \\
Loss of taste and smell & $1(5.5 \%)$ \\
Physician & $1(5.5 \%)$ \\
Nurse & \\
COVID-19 antibody (IgM/lgG) results & $1(5.5 \%)$ \\
Positive COVID-19 IgM/lgG & $17(94.5 \%)$ \\
Negative COVID-19 IgM/lgG & $1(50 \%)$ \\
COVID-19 by RT-PCR results $(n=2)$ & $1(50 \%)$ \\
Positive & $1(100 \%)$ \\
Negative & $0(0 \%)$ \\
Outcome of COVID-19 ( $n=1)$ & $1(100 \%)$ \\
Cured & \\
Complicated & \\
Discontinuation for 30 days & \\
\hline
\end{tabular}

\section{Discussion}

In the current study, we first surveyed all patients for COVID-19 symptoms and COVID-19 rapid IgM/IgG antibodies. Patients with COVID-19-related symptoms and/or positive antibodies were further subjected to RT-PCR testing. The preprocedural frequency of COVID-19 antibodies among the included patients was $25.3 \%(26 / 103)$, and the majority $88.5 \%(23 / 26)$ of COVID-19 antibody positive patients were asymptomatic. RT-PCR was detected in all $(n=3)$ symptomatic patients and in $61.5 \%$ of COVID-19 antibody-positive patients. There is no postprocedure infection in all enrolled patients, based on symptoms screening.

Symptom-based screening alone is not helpful in selecting patients prior to GIT procedures during the COVID-19 pandemic [15].. Not only was the positive predictive value of COVID-19 symptoms low (2.46\%), but positive RT-PCR tests were also detected in asymptomatic patients prior to the procedures [15]. In support of these findings, $13 \%$ of asymptomatic patients had COVID-19, as detected by RT-PCR in our study. These data highlighted the importance of RT-PCR in the prescreening of patients prior to GIT procedures. However, universal RT-PCR testing prior to GIT procedures is not without limitations. One concern is the accuracy of the currently available assays $[16,17]$. In addition, RT-PCR testing is time consuming and may not be a suitable prescreening test for urgent and semiurgent procedures. Indeed, a 15.3 to $16.6 \%$ increase in colorectal cancer deaths, likely related to delays in diagnosis during the pandemic, was reported [18]. Moreover, RT-PCR is an expensive test and may not be affordable in a country with limited resources, such as Egypt. Although it cannot replace preprocedural RT-CR universal screening, preprocedural RT-PCR screening in symptomatic and/or COVID-19 antibodypositive patients may be more economical for lowincome countries.

Polymerase chain reaction testing is the gold standard in COVID-19 diagnosis, yet the uncertainty of its accuracy should not be ignored. This suggests that the preprocedural clinical evaluation of COVID-19 based on symptoms, risk factors, and disease prevalence is of paramount importance. All symptomatic patients $(n=3)$ in the current study had COVID-19, as confirmed by RT-PCR. In contrast, Bowyer et al. had 119 symptomatic patients who underwent endoscopic evaluation had negative RT-PCR results prior to endoscopy [15]. This discrepancy may be related to the fact that all symptomatic patients in our study had highly suggestive COVID19 symptoms (fever $\geq 38^{\circ} \mathrm{C}$ ); on the other hand, many patients in the Bowyer et al. study presented with known GI symptoms. 
The accuracy of COVID-19 antibody tests in prescreening for COVID-19 has not yet been validated. COVID-19 antibody was detected in 1.9\% of Spanish patients screened before endoscopy [11]. The frequency of COVID-19 antibodies among Egyptian HCWs ranged from 12.2 to $18.2 \%$, of which $33.3-35 \%$ had positive COVID-19 RT-PCR results [14, 19]. A higher rate of COVID-19 antibodies (25.3\%) in patients was detected in our study, which may be explained by the variable prevalence of COVID-19 in different countries as well as the variable sensitivity of the kits used. Notably, $61.5 \%$ of COVID-19 antibody-positive patients had positive RTPCR results.

The incidence of preprocedural COVID-19 among patients undergoing GIT procedures is variable. In a multicenter, retrospective, Italian survey, the preprocedural rate of RT-PCR among patients undergoing ERCP was $2.7 \%$ [20]. Lower rates of $0.8 \%, 0.14 \%$, and $0.96 \%$ were reported in Winnebago [15], California [21], and New York City [22], respectively. The high rate (15.5\%) of COVID-19 in our patients may reflect the high prevalence of COVID-19 during the period of the study in Egypt.

The rate of COVID-19 among HCWs at GIT facilities ranged from 4.3 to $15.8 \%[20,23]$. A similar rate (13.5\%) was confirmed by RT-PCR among Egyptian HCWs at the GIT facility [19]. The lower rate (5.5\%) in our study may be explained by the fact that RT-PCR was used in symptomatic health care workers only. Indeed, COVID-19 was detected in $16.1 \%$ of asymptomatic HCWs in the GIT department [19] and the emergency department (14.3\%) using RT-PCR [14].

The advantages of our study are that we conducted the study during the peak of the 1st wave of the COVID-19 pandemic in Egypt, used a simple combination of clinical and serological tests to detect patients with a high risk for COVID-19, and tested them with RT-PCR. The limitations of our study include the single center study, a small sample size, and the lack of all patients tested COVID-19 with RT-PCR.

\section{Conclusion}

Preprocedural COVID-19 RT-PCR screening in symptomatic patients and/or COVID-19 antibody-positive patients is recommended prior to gastrointestinal procedures. The absence of postprocedure symptomatic COVID-19 in our study might be an indication that the screening methods and PPE used are adequate preventive tools in low-income countries.

\section{Abbreviations}

CRP: C-reactive protein; DBE: Double balloon enteroscope; DM: Diabetes mellitus; EGD: Esophagogastroduconoscopy; ERCP: Endoscopic Retrograde
Cholangiopancreatography; EUS: Endoscopic ultrasound; GIT: Gastrointestinal tract; HCC: Hepatocellular carcinoma; HCWs: Health care workers; HTN: Hypertension; PEG: Percutaneous endoscopic gastrostomy; PPE: Personal protective equipment; PTD: Percutaneous transhepatic drainage; RFA: Radiofrequency ablation; TACE: Transarterial chemoembolization.

\section{Acknowledgements}

We appreciate the effort of all medical staff who agreed to participate in this study.

\section{Authors' contributions}

$A E$ and $A E$ designed and coordinated the study; $O M O, A H, A S M, M E, R E, S M$, $A E, K M, S E$, and MA collected and interpreted the data; AE wrote the manuscript; $A E$ revised the article; the authors read and approved the final version of the manuscript.

\section{Funding}

The authors declare that they have no known competing financial interests or personal relationships that could have appeared to influence the work reported in this paper.

\section{Availability of data and materials}

All data generated or analyzed during this study are included in this published article.

\section{Declarations}

\section{Ethics approval and consent to participate}

The study was approved by the ethical committee of the Faculty of Medicine, Al-Azhar University, Cairo, Egypt (Med._147Med.Research. COVID-19 Screening Before Gastrointestinal Procedures._00000175). Informed consent was obtained from all individual participants included in the study.

\section{Consent for publication}

Not applicable

\section{Competing interests}

The authors declare that they have no competing interests.

\section{Author details}

'Department of Internal Medicine, Al-Azhar University, Nasr City, Cairo 11884, Egypt. ${ }^{2}$ Department of Clinical Pathology, Faculty of Medicine (for girls), Al-Azhar University, Cairo 11754, Egypt. ${ }^{3}$ Department of Surgery, Al-Azhar University, Cairo 11884, Egypt.

Received: 8 December 2021 Accepted: 2 February 2022

Published online: 09 February 2022

\section{References}

1. WHO (2020) Coronavirus disease (COVID-2019) situation reports. situation report - 51, 2020. Available:https://www.who.int/docs/default-source/ coronaviruse/situation-reports/20200311-sitrep-51-covid-19.pdf?sfvrsn= 1 ba62e57_10. https://doi.org/10.26524/royal.37.23

2. WHO (2020) Coronavirus disease (COVID-2019) situation reports. Situation report - 64, 2020. Available:https://www.who.int/docs/defaultsource/coronaviruse/situation-reports/20200324-sitrep-64-covid-19.pdf? sfvrsn=703b2c40_2. https://doi.org/10.26524/royal.37.23

3. World Health Organization c (2020) Coronavirus disease (COVID-19) situation report. Available: https://covid19. who.int/?gclid=CjwKCAjwps75BRA cEiwAEiACMWKO3W5tPwFgZ3enShftbVmXD0XB9_NLA4MqBOpCwxag0 n63LfXwWxoCchcQAvD_BwE; 2020 [Accessed 11 Aug 2020].

4. Parasa S, Reddy N, Faigel DO, Repici A, Emura F, Sharma P (2020) Global impact of the COVID-19 pandemic on endoscopy: an international survey of 252 centers from 55 countries. Gastroentrology 159(4):1579-1581. https://doi.org/10.1053/j.gastro.2020.06.009

5. Salerno R, Conti CB, De Silvestri A, Campbell Davies SE, Mezzina N, Ardizzone S (2020) The impact of covid-19 pandemic on urgent endoscopy in 
Italy: a nation-wide multicenter study. Scand J Gastroenterol 55:870-876. PMID: 32615891. https://doi.org/10.1080/00365521.2020.1782466

6. Uzair M, Aslam S, Farooq MA, Mansoor H, Hinna RE, Asghar A (2020) Impact of COVID-19 pandemic on the gastroenterology practice in a tertiary care hospital in Lahore. PAFMJ 70(1):S321-S325. https://doi.org/ 10.29054/apmc/2021.709

7. Xiao F, Tang M, Zheng X, Liu Y, Li X, Shan H (2020) Evidence for gastrointestinal infection of SARS-CoV-2. Gastroenterology 158:1831-1833.e3. PMID: 32142773. https://doi.org/10.1053/j.gastro.2020.02.055

8. Podboy A, Cholankeril G, Cianfichi L, Guzman E Jr, Ahmed A, Banerjee S (2020) Implementation and impact of universal preprocedure testing of patients for COVID-19 before endoscopy. Gastroenterology 159:15861588.e4. PMID: 32562723. https://doi.org/10.1053/j.gastro.2020.06.022

9. Joint gastroenterology society message: COVID-19 use of personal protective equipment in Gl endoscopy. URL: https://www.asge.org/home/ advancededucation-training/covid-19-asge-updates-for-members/jointgastroenterology-societymessage-covid-19-use-of-personal-protectiveequipment-in-gi-endoscopy/; 2020. doi: https://doi.org/10.1053/j.gastro. 2020.05.061.

10. Chiu PWY, Ng SC, Inoue H, Reddy DN, Hu EL, Cho JY (2020) Practice of endoscopy during COVID-19 pandemic: position statements of the Asian Pacific Socity for Digestive Endoscopy (APSDE-COVID statement). Gut 69:991-996. https://doi.org/10.1136/gutjnl-2020-321185

11. Camba AH, Reyes RM, Hernandez-Guerra M, Amato OA, Bennemann $P$, Machin SD, Medina JA (2021) Pre-procedural antibody testing for SARSCoV-2 in routine endoscopic practice. Rev Esp Enferm Dig 113(2):116118. https://doi.org/10.17235/reed.2020.7434/2020

12. Grazioli LM, Milluzzo SM, Spada C (2020) Safe endoscopy during the COVID-19 pandemic. Gastrointest Endosc 92(6):1274-1275. https://doi. org/10.1016/j.gie.2020.07.058

13. Haberman R, Axelrad J, Chen A, Castillo R, Yan D, Izmirly P, Neimann A, Adhikari S, Hudesman D, Scher JU (2020) Covid-19 in immune-mediated inflammatory diseases - case series from New York. N Engl J Med 383:85-88. PMID: 32348641. https://doi.org/10.1056/NEJMc2009567

14. Abdelmoniem R, Fouad R, Shawky S, Amer K, Elnagdy T, Hassan WA, Ali AM, Ezzelarab M, Gaber Y, Badary HA, Musa S, Talaat H, Kassem AM, Tantawi O (2021) SARS-CoV-2 infection among asymptomatic healthcare workers of the emergency department in a tertiary care facility. J Clin Virol 134:104710. PMID: 33276180. https://doi.org/10.1016/j.jcv.2020. 104710

15. Bowyer B, Thukral C, Patel S, Dovalovsky K, Bowyer SG, Ford J, Fox T, Ringler $E$ (2021) Outcomes of symptom screening and universal COVID-19 reverse transcriptase polymerase chain reaction testing before endoscopy in a community-based ambulatory surgery center. Gastrointest Endosc 93: 1060-1064.e1. PMID: 33039400. https://doi.org/10.1016/j.gie. 2020.10.001

16. Corral JE, Hoogenboom SA, Kröner PT, Vazquez-Roque MI, Picco MF, MB FFAW (2020) COVID-19 polymerase chain reaction testing before endoscopy: an economic analysis. Gastrointest Endosc 92:524-534.e6. PMID: 32360302. https://doi.org/10.1016/j.gie.2020.04.049

17. Woloshin S, Patel N, Kesselheim AS (2020) False negative tests for SARSCoV-2 infection - challenges and implications. N Engl J Med 383:e38. PMID: 32502334. https://doi.org/10.1056/NEJMp2015897

18. Maringe C, Spicer J, Morris M, Purushotham A, Nolte E (2020) Sulvian R Rachet B, Aggarwal A (2020) The impact of the COVID-19 pandemic on cancer deaths due to delays in diagnosis in England, UK: a national, population-based, modeling study. Lancet Oncol 21:1023-1034. https:// doi.org/10.1016/s1470-2045(20)30388-0

19. Kassem AM, Talaat $H$, Shawky S, Fouad R, Amer K, Elnagdy T, Hassan WA, Tantawi O, Abelmoniem R, Gaber Y, Badary HA, Musa S (2020) SARS-CoV-2 infection among healthcare workers of a gastroenterological service in a tertiary care facility. Arab J Gastroenterol 21:151-155. PMID: 32732168. https://doi.org/10.1016/j.ajg.2020.07.005

20. Donato G, Forti E, Mutignani M, Laterra MA, Arese D, Coppola F, Zaccari P, Mariani A, Arcidiacono PG, Pigo F, Conigliaro R, Costa D, Tringali A, Lavagna A, Rocca R, Gabbiadini R, Fugazza A, Repici A, Fava G, Marini F, Mosca P, Urban F, Monica F, Crino SF, Gabbrielli A, Blois M, Binda C, Sbrancia M, Fabbri C, Frego R, Dinelli M, Imbesi V, Gambitta P, Balzarini M, Segato S, Grazioli LM, Spada C, Amato A, Venezia G, Aragona G, Rosa C, Alvisi C, Devani M, Manes G, Dell'Amico I, Gemme C, Reati R, Auriemma F, Mangiavillano B, Rodi M, Bertani H, Mazzucco D, Armellini E, Cantu
P, Penagini R, Occhipint P (2021) A multicenter survey on endoscopic retrograde cholangiopancreatography during the COVID-19 pandemic in northern and central Italy. Endosc Int Open 9:E629-E634. PMID: 33880 397. https://doi.org/10.1055/a-1380-3419

21. Podboy A, Cholankeril G, Cianfichi L EG Jr, Ahmed A, Banerjee S (2020) Implementation and impact of universal pre-procedure testing of patients for COVID-19 prior to endoscopy. Gastroenterology 159:15861588. https://doi.org/10.1053/j.gastro.2020.06.022

22. Dolinger MT, Kumta NA, Greenwald DA, Dubinsky MC (2020) Outcomes of universal pre-procedure COVID-19 testing prior to endoscopy in a tertiary care center in New York City. Gastroenterology 159:1962-1964. https://doi.org/10.1053/j.gastro.2020.07.015

23. Repici A, Aragona G, Cengia G, Cantu P, Spadaccini M, Maselli R, Carrara S, Anderloni A, Fugazza A, Pace F, Rosch T, ITALIAN GI-COVID19 Working Group (2020) Low risk of covid-19 transmission in Gl endoscopy. Gut 69:1925-1927. https://doi.org/10.1136/gutjnl-2020-321341

\section{Publisher's Note}

Springer Nature remains neutral with regard to jurisdictional claims in published maps and institutional affiliations.

\section{Submit your manuscript to a SpringerOpen ${ }^{\circ}$ journal and benefit from:}

- Convenient online submission

- Rigorous peer review

- Open access: articles freely available online

- High visibility within the field

- Retaining the copyright to your article

Submit your next manuscript at $\boldsymbol{\nabla}$ springeropen.com 